\title{
Trends in the prevalence of twenty health indicators among adolescents in United Arab Emirates: cross-sectional national school surveys from 2005, 2010 and 2016
}

Supa Pengpid ${ }^{1,2}$ and Karl Peltzer ${ }^{3 *}$

\begin{abstract}
Background: The aim of this study was to assess the trends in the prevalence of various health indicators among adolescents in United Arab Emirates (UAE).

Methods: Nationally representative data were analysed from 24,220 in-school adolescents (median age $=14$ years) that took part in three cross-sectional surveys (2005, 2010 and 2016) of the "UAE Global School-Based Student Health Survey (GSHS)".

Results: Significant improvements were identified among both girls and boys in the reduction of being physically attacked, inadequate fruit intake, inadequate vegetable consumption, loneliness, and among girls only poor oral hygiene ( $<2$ times tooth brushing/day) and among boys only, experiencing hunger and in physical fight. Significant rises were identified among both girls and boys in the prevalence of bullying victimization, overweight or obesity, leisure-time sedentary behaviour, injury and inconsistent washing hands prior to eating, and among boys only obesity and among girls only inadequate physical activity, and school truancy.

Conclusions: Several reductions but even more increases of poor health indicators were identified over three crosssectional surveys during a period of 11 years emphasizing the need for enhanced health promotion activities in this adolescent school population.
\end{abstract}

Keywords: Obesity, Health indicators, Mental health violence, Protective factors, Hygiene, Injury

\section{Background}

In United Arab Emirates (UAE), a high-income Arab country, $77 \%$ of all death are attributed to noncommunicable diseases (NCDs) [1]. The prevalence of NCDs (diabetes, cancer, chronic lung diseases and cardiovascular disease) is on the rise in countries of the Arab region, including the UAE [2]. Behavioural NCD health risk indicators, such as physical inactivity,

\footnotetext{
* Correspondence: kfpeltzer@gmail.com

${ }^{3}$ Department of Psychology, University of the Free State, Bloemfontein, South Africa

Full list of author information is available at the end of the article
}

unhealthy diets, tobacco use, and obesity, are very common among children and adults in the Arab region [2]. As stated by the World Health Organization (WHO), "alcohol use, dietary behaviours, drug use, hygiene, mental health, physical activity, protective factors, sexual behaviours, tobacco use, violence and unintentional injury" are the leading causes of morbidity/mortality among children and adults globally [3]. Monitoring various health indicators, such as nutrition and diet, substance use, physical activity, violence, injury and mental health, among adolescents over time may facilitate targeting intervention strategies [4-6]. 
Diverse results were found in research investigating trends in health indicators among adolescents $[5,6]$. For example, in a trend study among adolescents in the Philippines [5] poor hand hygiene behaviour decreased over time, while it increased in Oman [6], and interpersonal violence, injury and physical inactivity decreased, while the prevalence of fruit and vegetable intake (one study) increased $[5,6]$. In terms of injury and interpersonal violence, in a large study among adolescents in the UAE, $18 \%$ reported a physical injury in the past 12 months [7]. In a local study among adolescents in UAE, $15.4 \%$ of males and $8.0 \%$ of females reported physical violence (having been hit and pushed) in the past month [8]. In another study among 1054 school students in Dubai, peer violence (beating $39.4 \%$ and boxing 24.5\%) was commonly reported [9].

Regarding overweight and obesity, in a study among 6-19 year-old students in Abu Dhabi, UAE, 14.7\% were measured to have overweight and $18.9 \%$ obesity [10]. In a study among adolescents in public and private schools in Dubai, $72 \%$ reported inadequate fruit and vegetable intake [11]. In a meta-analytic review of physical activity among adolescents in the UAE, one in four had total sedentary behaviour with no physical activity [12]. In a cross-sectional study (2007-2009) among adolescents in UAE, the prevalence of current smokers was $14.0 \%$ [13]. In terms of mental health, in a sample of school adolescents $(\mathrm{N}=600)$ in the UAE, $17.2 \%$ were found to have depressive symptoms [14], and in another adolescent school sample $(\mathrm{N}=968)$ in UAE, the prevalence of anxiety disorders was $28 \%$ [15].

There is a major research gap in the assessment of trends in health indicators over time among adolescents in the Eastern Mediterranean region, such as in UAE. The present study aims to estimate trends of the prevalence of 20 different health and five protective indicators in the 2005, 2010 and 2016 UAE "Global School-based Student Health Survey (GSHS)". It is hypothesized that the prevalence of health indicators differs across the three GSHS from 2005, 2010 and 2016. Research results on trends of various health indicators may be beneficial for health promotion activities in schools [16].

\section{Methods}

\section{Participants and procedure}

Data from the 2005, 2010 and 2016 UAE cross-sectional GSHS were analysed [3]. A sampling design in two stages (first: schools selected with probability proportional to sample size, and second: classes of grades 8,9 , and 10 students within schools were randomly selected) was used to generate a national representative country sample [3]. All students in the selected classes were eligible to participate regardless of their age, and responded to a self-administered questionnaire [3]. For the 2005 UAE GSHS the response rate was $89 \%$, for $201091 \%$ and for the 2016 UAE GSHS 80\% [3]. The data and more detailed information on the study procedures can be accessed [3].

The GSHS core questionnaire assesses 10 modules: "alcohol use, dietary behaviours, drug use, hygiene, mental health, physical activity, protective factors, sexual behaviours that contribute to HIV infection, other sexually-transmitted infections, and unintended pregnancy, tobacco use, violence and unintentional injury." [3] All core modules of the questionnaire that were implemented in the 2005, 2010 and 2016 UAE GSHS were part of this analysis.

\section{Measures}

The questionnaire used is shown in Table 1 [3]. Overweight/obesity was classified as "more than +1 standard deviation (SD) and obesity more than +2 SD from the median body mass index by age and sex," using the 2007 WHO Child Growth reference [17]. The consumption of less than "two or more servings of fruits in a day" and less than "three or more servings of vegetables a day" were considered inadequate [18]. "Inadequate physical activity was defined as not daily at least 60 minutes of moderate to vigorous-intensity physical activity." [19] "Leisure-time sedentary behaviour was defined as spending three or more hours per day sitting." [20].

\section{Covariates}

We categorized age into three groups $(\leq 11-13,14-15$, and $\geq 16$ years), experience of hunger (as a proxy for socioeconomic status) into three groups (never, rarely or sometimes, and most of the time or always) and study year into three groups $(2005,2010$, and 2016), with the first value being the reference category, respectively.

\section{Data analysis}

Statistical analyses were conducted using "STATA software version 15.0 (Stata Corporation, College Station, Texas, USA)". Data were weighted for non-response and probability selection [3]. In order to test for differences in proportion Pearson Chi-square tests were utilized. Logistic regression analyses were applied to estimate each health indicator outcome adjusted by age group, socioeconomic status (experience of hunger) and study year for boys and girls, separately. In order to account for the sample weight and the multi-stage sampling design, Taylor linearization methods were applied. Results from the logistic regression analyses are shown as odds ratios (ORs) with 95\% confidence intervals (CIs). Missing values were excluded from the analysis. $\mathrm{P}<0.05$ was considered significant. 


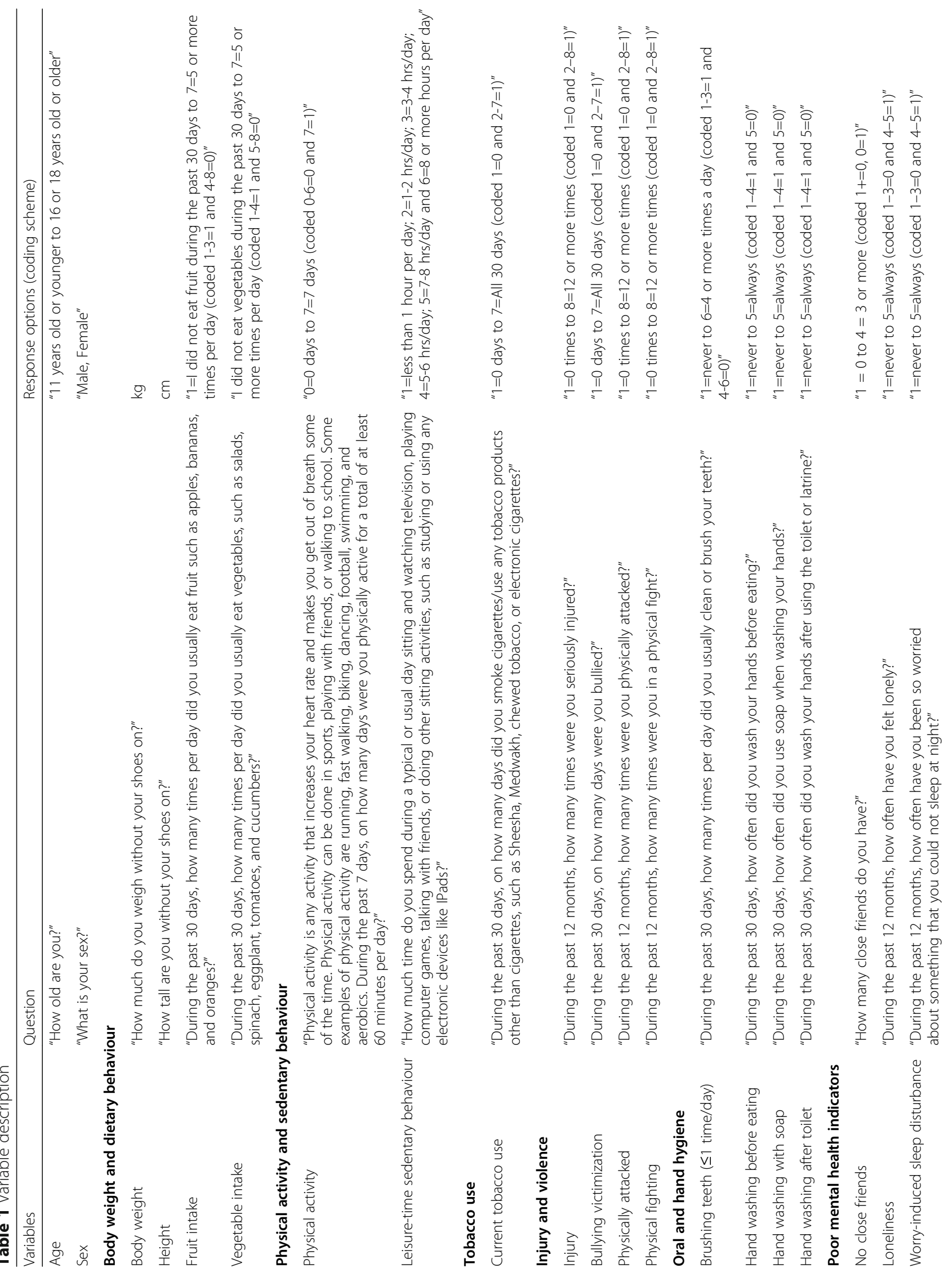




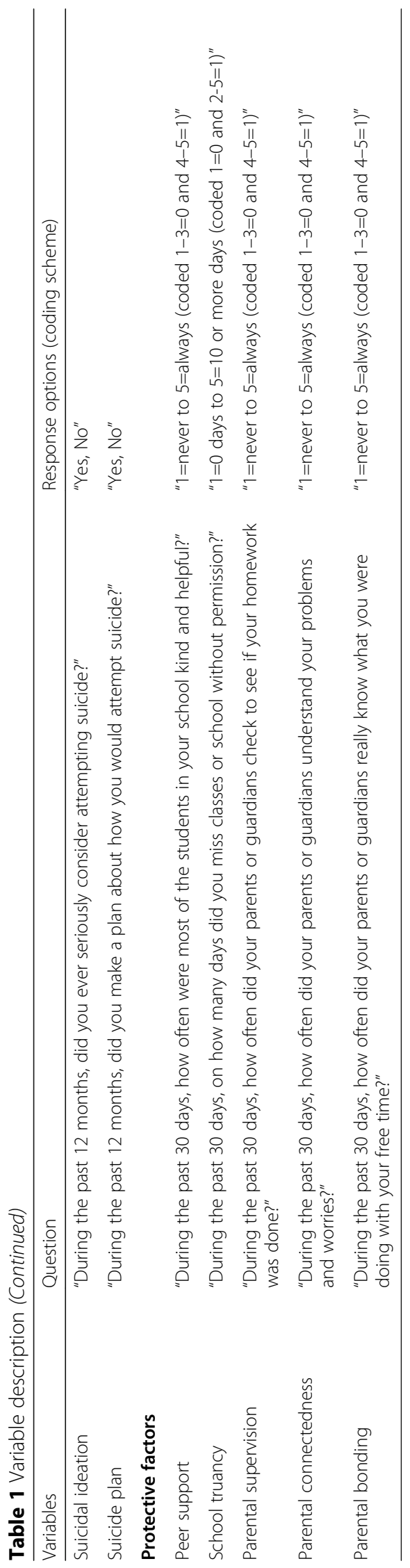




\section{Results}

\section{Description of the study sample}

Across the 2005, 2010, and 2016 UAE GSHS the overall sample consisted of 24,220 school-going adolescents, $52.2 \%$ females and $47.8 \%$ males (median age $=14$ year, interquartile range $=2$ years). The number of older adolescents increased across the three different assessment years $(P<0.001)$ (see Table 2$)$.

\section{Health indicator outcomes \\ Overweight and poor diet}

Among students, $21.2 \%$ of males and $21.7 \%$ of females were overweight or obese in 2005 , while this significantly increased among boys in 2010 (43.7\%) and 2016 (42.1\%) as well as significantly increased but to a lesser extent among girls than boys in 2010 (36.0\%) and 2016 (35.6\%). Likewise, the prevalence of obesity significantly increased over time among boys but not among girls. More than two in three male students (68.7\%) and $75.2 \%$ female students had less than two servings of fruits per day in 2005, while these prevalences significantly decreased between both sexes in 2016. Inadequate vegetable intake significantly reduced between both sexes from 2005 to 2016. Among girls, the proportion of experiencing hunger reduced from 2005 to 2010 but stayed unchanged from 2005 to 2016, while hunger experiences reduced among boys from 2005 to 2016.

\section{Physical activity and sedentary behaviour}

The prevalence of inadequate physical activity did not change among boys but increased among girls over time, and the proportion of sedentary behabiour significantly increased from 2005 to 2016 among both boys and girls.

\section{Tobacco use}

The prevalence of current tobacco use increased among both boys and girls over time but this was not statistically significant.

\section{Injury and violence}

Having been physically attacked and involved in physical fighting significantly decreased among boys and physical assault decreased among girls from 2005 to 2016, while the prevalence of injury increased significantly in both sexes from 2005 to 2016. Bullying victimization increased among both boys and girls from 2005 to 2016 .

\section{Oral and hand hygiene}

The prevalence of inadequate oral hygiene (tooth brushing) was $48.6 \%$ among male and $37.9 \%$ among female students in 2005, while this remained unchanged among boys a significant reduction was found among girls in 2010 and 2016. Not always washing hands prior to eating significantly increased among both sexes from 2005 to 2010 and 2016, while the other two poor hand washing indicators (not always washing hands after toilet use and with soap) did not significantly change over time among both boys and girls.

\section{Poor mental health}

Loneliness decreased among both boys and girls from 2005 to 2016, while there was no significant change for the remaining four poor mental health indications

Table 2 Sample characteristics of school adolescents: 2005, 2010 and 2016 surveys in UAE

\begin{tabular}{|c|c|c|c|c|}
\hline \multirow[t]{2}{*}{ Variable } & $2005(N=15,790)$ & $2010(N=02,581)$ & $2016(N=05,849)$ & Total $(N=24,220)$ \\
\hline & $\mathrm{N}(\%)$ & N (\%) & N (\%) & N (\%) \\
\hline \multicolumn{5}{|l|}{ Gender } \\
\hline $\begin{array}{l}\text { Male } \\
\text { Female } \\
\text { Missing }\end{array}$ & $\begin{array}{l}7741(50.0) \\
7893(50.0) \\
156(0.9)\end{array}$ & $\begin{array}{l}1079(42.1) \\
1483(57.9) \\
19(0.8)\end{array}$ & $\begin{array}{l}2763(49.7) \\
3041(50.3) \\
45(0.7)\end{array}$ & $\begin{array}{l}11,583(47.8) \\
12,417(52.2) \\
220(0.8)\end{array}$ \\
\hline \multicolumn{5}{|l|}{ Age in years } \\
\hline $\begin{array}{l}11 \text { or younger } \\
12 \\
13 \\
14 \\
15 \\
16 \text { years or older } \\
\text { Missing }\end{array}$ & $\begin{array}{l}404(2.6) \\
2150(13.1) \\
3630(22.3) \\
3827(23.6) \\
3212(21.2) \\
2373(17.2) \\
194(1.1)\end{array}$ & $\begin{array}{l}9(0.4) \\
123(4.3) \\
669(23.1) \\
846(31.8) \\
664(29.2) \\
259(11.2) \\
11(0.4)\end{array}$ & $\begin{array}{l}41(0.7) \\
281(4.7) \\
911(13.9) \\
1126(19.8) \\
1153(19.8) \\
1314(41.1) \\
23(0.4)\end{array}$ & $\begin{array}{l}454(1.2) \\
2554(7.1) \\
5210(18.7) \\
5799(24.0) \\
5029(22.6) \\
4946(26.4) \\
228(0.6)\end{array}$ \\
\hline \multicolumn{5}{|l|}{ Grade } \\
\hline $\begin{array}{l}7 \\
8 \\
9 \\
10 \text { and other } \\
\text { Missing }\end{array}$ & $\begin{array}{l}4215(26.9) \\
4064(25.4) \\
3851(24.2) \\
3431(23.5) \\
228(1.4)\end{array}$ & $\begin{array}{l}945(33.7) \\
939(33.9) \\
677(32.4) \\
0 \\
20(0.7)\end{array}$ & $\begin{array}{l}244(4.6) \\
1215(16.8) \\
1156(22.2) \\
3118(35.9) \\
116(1.9)\end{array}$ & $\begin{array}{l}5404(18.7) \\
6219(23.7) \\
5684(25.4) \\
6519(32.2) \\
364(1.5)\end{array}$ \\
\hline
\end{tabular}


(worry-induced sleep disturbance, having no close friends, suicide plan and suicidal ideation).

\section{Protective factors}

Among both girls and boys, peer support did not change from 2005 to 2016, and truancy did not change among boys but increased among girls over time. Among the three parental support indicators (bonding, connectedness and supervision), all remained unchanged over time except for a decrease in parental supervision among boys and girls (see Tables 3 and 4).

\section{Discussion}

The study found across the 2005, 2010 and 2016 GSHS in UAE a significant reduction of being physically attacked, inadequate fruit intake, inadequate vegetable

Table 3 Health risk indicators in 2005, 2010 and 2016 among male school adolescents, UAE

\begin{tabular}{|c|c|c|c|c|c|}
\hline \multirow[t]{2}{*}{ Variable } & \multirow{2}{*}{$\begin{array}{l}2005 \\
\text { N (\%) }\end{array}$} & \multirow{2}{*}{$\begin{array}{l}2010 \\
\text { N (\%) }\end{array}$} & \multirow{2}{*}{$\begin{array}{l}2016 \\
\text { N (\%) }\end{array}$} & \multicolumn{2}{|c|}{ Change over time compared to 2005} \\
\hline & & & & $\begin{array}{l}2010 \\
\text { Adjusted }^{\mathrm{a}} \text { OR (95\% Cl) }\end{array}$ & $\begin{array}{l}2016 \\
\text { Adjusted }^{\mathrm{a}} \text { OR (95\% Cl) }\end{array}$ \\
\hline \multicolumn{6}{|l|}{ Body weight and dietary behaviour } \\
\hline Overweight or obesity & $1510(21.2)$ & $421(43.7)$ & $1074(42.1)$ & $2.93(2.45,3.50)^{* * *}$ & $2.82(2.41,3.32)^{* * *}$ \\
\hline Obesity & $928(13.2)$ & $186(19.8)$ & $556(21.3)$ & $1.69(1.37,2.10)^{* * *}$ & $1.77(1.46,2.14)^{* * *}$ \\
\hline Fruits $<2$ day & $5275(68.7)$ & $753(70.6)$ & $1695(61.6)$ & $1.07(0.93,1.23)$ & $0.63(0.53,0.76)^{* * *}$ \\
\hline Vegetable $<3$ day & $6205(81.0)$ & $853(79.9)$ & $2159(78.4)$ & $0.92(0.79,1.07)$ & $0.77(0.66,0.89)^{* * *}$ \\
\hline Went hungry (mostly/always) & $815(10.0)$ & $59(6.2)$ & $241(7.9)$ & $0.60(0.43,0.85)^{* *}$ & $0.70(0.55,0.90)^{* *}$ \\
\hline \multicolumn{6}{|l|}{ Physical activity and sedentary behaviour } \\
\hline Inadequate physical activity & $5768(77.1)$ & $797(77.5)$ & $2150(79.7)$ & $1.04(0.85,1.27)$ & $1.10(0.94,1.29)$ \\
\hline Leisure-time sedentary behaviour & $2814(38.0)$ & $475(45.0)$ & $1322(51.1)$ & $1.27(1.04,1.55)^{*}$ & $1.53(1.30,1.80)^{* * *}$ \\
\hline Current tobacco use & $1394(13.2)$ & $251(19.8)$ & $705(21.3)$ & $1.24(0.98,1.56)$ & $1.10(0.88,1.36)$ \\
\hline \multicolumn{6}{|l|}{ Injury and violence } \\
\hline Any serious injury (past year) & $2243(38.4)$ & $481(51.8)$ & $1219(51.0)$ & $1.81(1.57,2.09)^{* * *}$ & $1.72(1.50,1.97)^{* * *}$ \\
\hline Bullied (past month) & $1714(24.5)$ & $260(25.9)$ & $810(29.9)$ & $1.14(0.95,1.36)$ & $1.41(1.20,1.67)^{* * *}$ \\
\hline In physical fight (past year) & $4329(56.9)$ & $646(60.9)$ & $1403(50.8)$ & $1.20(1.01,1.44)^{*}$ & $0.84(0.71,0.99)^{*}$ \\
\hline Physically attacked (past year) & $3100(40.8)$ & $448(42.0)$ & $916(32.8)$ & $1.15(0.97,1.37)$ & $0.79(0.69,0.91)^{* *}$ \\
\hline \multicolumn{6}{|l|}{ Oral and hand hygiene } \\
\hline Brushing teeth ( $\leq$ once/day) & 3665 (48.6) & $498(46.8)$ & $1270(46.1)$ & $0.91(0.73 .1 .12)$ & $0.83(0.68,1.02)$ \\
\hline Wash hands before eating (not always) & $2210(29.6)$ & $413(38.7)$ & $1081(41.6)$ & $1.53(1.19,1.97)^{* * *}$ & $1.67(1.34,2.08)^{* * *}$ \\
\hline Wash hands after toilet/ latrine use (not always) & $1271(17.1)$ & $203(19.3)$ & $554(19.2)$ & $1.24(1.02,1.51)^{*}$ & $1.13(0.90,1.43)$ \\
\hline Wash hands with soap (not always) & $2580(34.9)$ & $363(34.0)$ & $912(33.1)$ & $0.97(0.82,1.14)$ & $0.92(0.78,1.10)$ \\
\hline \multicolumn{6}{|l|}{ Poor mental health } \\
\hline Having no close friends & $478(6.6)$ & $74(7.2)$ & $205(7.0)$ & $1.16(0.86,1.56)$ & $1.14(0.84,1.55)$ \\
\hline Loneliness (past year) & $967(13.1)$ & $166(15.9)$ & $329(11.6)$ & $1.32(1.03,1.69)^{*}$ & $0.76(0.64,0.90)^{* *}$ \\
\hline Worry-induced sleep disturbance (past year) & $792(10.6)$ & $140(13.0)$ & $331(11.9)$ & $1.35(1.05,1.73)^{*}$ & $1.00(0.85,1.19)$ \\
\hline Suicidal ideation (past year) & $945(13.4)$ & $147(14.7)$ & $199(12.5)$ & $0.93(0.70,1.22)$ & $0.95(0.69,1.30)$ \\
\hline Suicide plan (past year) & $692(10.3)$ & $145(14.2)$ & $154(9.5)$ & $1.29(1.03,1.57)^{*}$ & $0.93(0.69,1.22)$ \\
\hline \multicolumn{6}{|l|}{ Protective factors } \\
\hline Truancy (past month) & $2461(34.0)$ & $387(38.3)$ & $1108(40.2)$ & $1.19(0.93,1.53)$ & $1.10(0.87,1.39)$ \\
\hline Peer support (mostly/always) & $4167(55.6)$ & $590(56.7)$ & $1521(56.9)$ & $1.00(0.82,1.23)$ & $1.03(0.86,1.24)$ \\
\hline Parents/guardians supervision (mostly/always) & $4055(54.8)$ & $522(52.3)$ & $1248(44.7)$ & $0.90(0.74,1.10)$ & $0.72(0.60,0.85)^{* * *}$ \\
\hline Parents/guardians connectedness (mostly/always) & $3634(50.1)$ & $465(45.0)$ & $1162(45.2)$ & $0.79(0.67,0.94)^{* *}$ & $0.88(0.76,1.02)$ \\
\hline Parents or guardians bonding (mostly/always) & $3935(52.9)$ & $478(46.1)$ & 1319 (49.9) & $0.75(0.62,0.91)^{* *}$ & $1.03(0.87,1.21)$ \\
\hline
\end{tabular}

OR Odds Ratio, $\mathrm{Cl}$ Concidence Interval

${ }^{a}$ Adjusted for age group, experiences of hunger (proxy measure for socioeconomic status) (except for hungry as outcome) and study year; ${ }^{* * *} P<0.001$;

${ }^{*} P<0.01$; ${ }^{*} P<0.05$; 
Table 4 Health risk indicators in 2005, 2010 and 2016 among female school adolescents, UAE

\begin{tabular}{|c|c|c|c|c|c|}
\hline \multirow[t]{2}{*}{ Variable } & \multirow{2}{*}{$\begin{array}{l}2005 \\
\text { N (\%) }\end{array}$} & \multirow{2}{*}{$\begin{array}{l}2010 \\
\text { N (\%) }\end{array}$} & \multirow{2}{*}{$\begin{array}{l}2016 \\
\text { N (\%) }\end{array}$} & \multicolumn{2}{|c|}{ Change over time compared to 2005} \\
\hline & & & & 2010 Adjusted $^{\mathrm{a}}$ OR $(95 \%$ Cl) & 2016 Adjusted $^{\mathrm{a}}$ OR $(95 \% \mathrm{Cl})$ \\
\hline \multicolumn{6}{|l|}{ Body weight and dietary behaviour } \\
\hline Overweight or obesity & $1589(21.7)$ & $484(36.0)$ & $1013(35.6)$ & $2.05(1.69,2.48)^{* * *}$ & $2.09(1.77,2.46)^{* * *}$ \\
\hline Obesity & $782(11.0)$ & $177(12.4)$ & $383(13.0)$ & $1.20(0.93,1.56)$ & $1.16(0.98,1.39)$ \\
\hline Fruits $<2$ day & $5798(75.2)$ & $1110(76.2)$ & $2138(68.6)$ & $1.05(0.85,1.29)$ & $0.62(0.49,0.80)^{* * *}$ \\
\hline Vegetable $<3$ day & $6602(84.7)$ & $1232(84.8)$ & $2459(79.5)$ & $0.96(0.80,1.17)$ & $0.63(0.52,0.78)^{* * *}$ \\
\hline Went hungry (mostly/always) & $672(8.9)$ & $72(5.0)$ & $332(9.9)$ & $0.56(0.38,0.85)^{* *}$ & $1.00(0.77,1.30)$ \\
\hline \multicolumn{6}{|l|}{ Physical activity and sedentary behaviour } \\
\hline Inadequate physical activity & $6513(83.8)$ & $1250(86.7)$ & $2660(88.6)$ & $1.26(0.99,1.60)$ & $1.37(1.14,1.66)^{* * *}$ \\
\hline Leisure-time sedentary behaviour & 3019 (39.6) & $790(56.0)$ & $1974(66.7)$ & $1.90(1.53,2.30)^{* * *}$ & $2.63(2.21,3.12)^{* * *}$ \\
\hline Current tobacco use & $453(5.7)$ & $121(9.3)$ & $293(10.4)$ & $1.81(1.15,2.84)^{*}$ & $1.43(0.98,2.10)$ \\
\hline \multicolumn{6}{|l|}{ Injury and violence } \\
\hline Any serious injury (past year) & $1243(19.0)$ & $464(35.1)$ & $940(34.5)$ & $2.48(2.07,2.97)^{* * *}$ & $2.22(1.84,2.67)^{* * *}$ \\
\hline Bullied (past month) & $1292(17.2)$ & $297(20.7)$ & $605(20.5)$ & $1.37(1.11,1.69)^{* *}$ & $1.27(1.05,1.53)^{*}$ \\
\hline In physical fight (past year) & $2329(29.5)$ & $539(36.5)$ & $806(26.5)$ & $1.48(1.26,1.74)^{* * *}$ & $0.91(0.73,1.13)$ \\
\hline Physically attacked (past year) & $1838(23.0)$ & $411(28.5)$ & $555(18.2)$ & $1.53(1.24,1.88)^{* *}$ & $0.79(0.64,0.97)^{*}$ \\
\hline \multicolumn{6}{|l|}{ Oral and hand hygiene } \\
\hline Brushing teeth ( $\leq$ once/day) & $2801(37.9)$ & $450(31.4)$ & $870(28.3)$ & $0.76(0.63,0.93)^{* *}$ & $0.60(0.48,0.75)^{* * *}$ \\
\hline Wash hands before eating (not always) & 2385 (31.9) & $603(40.5)$ & $1431(49.0)$ & $1.44(1.16,1.78)^{* * *}$ & $2.03(1.67,2.47)^{* * *}$ \\
\hline Wash hands after toilet/ latrine use (not always) & $1149(15.3)$ & $236(15.6)$ & $549(17.7)$ & $1.10(0.89,1.36)$ & $1.15(0.98,1.35)$ \\
\hline Wash hands with soap (not always) & $2175(28.3)$ & $496(32.7)$ & $912(30.6)$ & $1.27(0.99,1.62)$ & $1.19(0.97,1.47)$ \\
\hline \multicolumn{6}{|l|}{ Poor mental health } \\
\hline Having no close friends & $489(6.2)$ & $76(5.3)$ & $204(6.6)$ & $0.89(0.68,1.17)$ & $1.01(0.81,1.26)$ \\
\hline Loneliness (past year) & $1368(17.7)$ & $260(17.9)$ & $485(16.0)$ & $1.14(0.93,1.39)$ & $0.72(0.59,0.88)^{* *}$ \\
\hline Worry-induced sleep disturbance (past year) & $1360(18.1)$ & $270(19.4)$ & $628(20.5)$ & $1.20(0.97,1.49)$ & $0.95(0.79,1.14)$ \\
\hline Suicidal ideation (past year) & $982(12.5)$ & $240(17.5)$ & $289(15.2)$ & $1.13(0.85,1.51)$ & $0.98(0.76,1.06)$ \\
\hline Suicide plan (past year) & $717(9.2)$ & $234(16.9)$ & $241(12.4)$ & $1.65(1.32,2.05)^{* * *}$ & $1.25(0.97,1.64)$ \\
\hline \multicolumn{6}{|l|}{ Protective factors } \\
\hline Truancy (past month) & $2089(28.3)$ & $526(37.2)$ & $1335(41.4)$ & $1.63(1.32,2.01)^{* * *}$ & $1.41(1.03,1.92)^{*}$ \\
\hline Peer support (mostly/always) & $5488(71.0)$ & $1036(72.0)$ & $2104(68.0)$ & $1.00(0.83,1.21)$ & $0.87(0.70,1.07)$ \\
\hline Parents/guardians supervision (mostly/always) & $3646(47.9)$ & $588(41.6)$ & $1221(39.0)$ & $0.75(0.59,0.95)^{*}$ & $0.78(0.63,0.98)^{*}$ \\
\hline Parents/guardians connectedness (mostly/always) & $3960(51.2)$ & $691(47.1)$ & $1428(47.7)$ & $0.80(0.67,0.94)^{* *}$ & $0.96(0.82,1.13)$ \\
\hline Parents or guardians bonding (mostly/always) & $4477(58.3)$ & $756(51.6)$ & $1676(56.6)$ & $0.72(0.62,0.84)^{* * *}$ & $1.06(0.87,1.29)$ \\
\hline
\end{tabular}

OR Odds Ratio, $\mathrm{Cl}$ Concidence Interval

adjusted for age group, experiences of hunger (proxy measure for socioeconomic status) (except for hungry as outcome) and study year; ${ }^{* * *} \mathrm{P}<0.001$; ${ }^{* * P}<0.01 ; * \mathrm{P}<0.05$;

consumption, and loneliness among both boys and girls, and among girls only poor oral hygiene $(<2$ times tooth brushing/day) and among boys only, experiencing hunger and in physical fight. Among both boys and girls significant rises were identified in the prevalence of bullying victimization, overweight or obesity, leisuretime sedentary behaviour, injury and not always washing hands prior to eating, and among boys only obesity and among girls only inadequate physical activity, and school truancy.
In 2004, the national health promoting school network was implemented in UAE, including the promotion of healthy behaviour (diet, physical activity, safety, mental, emotional and social health, comprehensive screening [21]. In a recent study among adolescents in Dubai, UAE, more than one in four had limited health literacy, calling for health literacy training among UAE adolescents [22]. A strengthening of the health promotion school activities is indicated in order to improve on some of health indicators. 
The study showed a stark increase of overweight and obesity in this study from 2005 to 2010 and 2016, in both boys and girls and even a greater increase among boys than girls did. Previous studies, (e.g. [10]) have reported high rates of overweight and obesity among adolescents in UAE, including a steady rise in obesity, especially in boys [23]. These findings seems to be consistent with global increases in the prevalence of obesity among adolescents from 1975 to 2016 [24]. In the 2005 UAE GSHS insufficient fruit and vegetable consumption was high and further increased to 2016. Similar increases in inadequate fruit and vegetable intake were also shown in a trend study in Oman [6] and other countries in the Arab region [25]. The prevalence of experiencing hunger was low and significantly reduced among boys but not girls from 2005 to 2016.

Violence-related events (in a physical fight and physical assault) reduced in the present study over time. Similar results were found in four other research studies [4, 26-28], while in Oman [6], the Philippines [5] and Venezuela [29] one or more types of interpersonal violence increased. Several local studies among adolescents in UAE have stressed the importance of interpersonal violence $[8,9]$ and this study found an increase in bullying victimization among boys and girls over time. This result may call for anti-bullying programmes among school adolescents in UAE. However, among both boys and girls the prevalence of annual injury significantly increased, which is consistent with the trend study in the Philippines [5]. On the other hand, the injury prevalence among adolescents in Morocco declined [30], and no significant trend differences were identified in Oman [6]. The large increase in the occurrence of injuries calls for school safety promotion and injury prevention among adolescents in UAE.

Physical inactivity increased among female students in this study. Henry et al. [31] concluded from a study among female adolescents in the UAE that the physical activity was very low, attributing this to weather and cultural restrictions as well as unconducive community attitudes [31]. Leisure- time sedentary behaviour increased significantly in this study to $51.1 \%$ in boys and $66.7 \%$ in girls, which is much higher than the global average in school-going adolescents (26.4\%) [32] and the highest among 10 Eastern Mediterranean countries [33]. Since in this study, leisure-time sedentary behaviour was assessed with a composite measure "sitting and watching television, playing computer games, talking with friends, or doing other sitting activities, such as studying or using any electronic devices like IPads" [3], we are not able to identify if a particular type of sedentary behaviour increased more than another type. Some studies, e.g., in the US, showed an increase of the use of recreational screen-based devices, such as electronic entertainment and computer use, among adolescents during the first decade of the 21st century [34], which may be applicable to the UAE too.
The proportion of inadequate tooth brushing ( $<$ twice/ day) was high across the three UAE GSHS ( $>46 \%$ in boys and $>30 \%$ in girls), significantly higher than among adolescents in Southeast Asia (22.4\%) [35]. In a survey among private school adolescent students in Abu Dhabi, Dubai, 63.6\% had sub-optional oral hygiene practices [36], and in a sample of adolescent school children in Sharjah, UAE, $19.8 \%$ of Emirati and $40.3 \%$ other Arabs engaged in inadequate tooth brushing ( $<2$ times/day) [37], indicating the importance of improving oral health hygiene in UAE. Poor hand washing before eating increased in both sexes in this study, which was similar in the Oman trend study [6], while poor hand hygiene decreased among adolescents in the Philippines [5]. In a study among primary school students in Sharjah, UAE, 27\% did not always wash hands before eating and $31 \%$ did not always wash hands after toilet use [38], and in Al Anin, UAE, among 15 to 55 year-olds from the community " $30 \%$ did not always wash their hands before and after eating and 20\% did not always wash their hands after using toilets." [39]. All the more, an improvement of hand hygiene behaviour among adolescents in UAE is indicated.

The prevalence of current tobacco use increased among both boys and girls over time but this was not statistically significant, and concur with previous investigations in the UAE [13]. On the other hand the prevalence of current tobacco use from the UAE Global Youth Tobacco Survey (GYTS) in 2005 (19.5\%) decreased to $12.2 \%$ in 2013 [40, 41]. In terms of four indicators of mental health (suicide plan, suicidal ideation, worry-induced sleep disturbance, and having no close friends), the study did not find significant changes over time, except for a decrease in loneliness in both sexes. While the prevalence of loneliness increased among both boys and girls over time in the Philippines trend study [5]. As shown in some previous studies among adolescents in UAE $[14,15]$, mental morbidity in the form of depressive and anxiety-related symptoms has been shown as to be a significant burden.

Consistent with previous studies [4-6], this survey found mixed results on protective factors, parental support indicators did not change except for a decrease of one parental indicator (parental supervision) among both girls and boys, peer support did not change, and school truancy increased among girls. For example, in the New Zealand trend study positive school and family connections became better over time [4], in the Oman trend study peer support increased over time [5], and in the Philippines trend study protective factors remained unchanged over time [6].

The present research findings may contribute to better targeting of specific health indicators among adolescents in health promotion activities in UAE. For example, school-based interventions can be effective in reducing 
excessive weight gain and in promotion of physical activity and fitness [42, 43]. After-school programmes can improve physical activity levels [44]. Dietary behaviours may be improved by implementing specific school food environment policies, such as the direct provision of healthy beverages and foods [45]. In the prevention of bullying and smoking different types of whole-school health interventions have shown to be effective. [46] Poor mental health (anxiety and depressive symptoms) among adolescents may be decreased by universal resilience-focused interventions (especially cognitivebehavioural therapy) [47]. Increased implementation of multi-level (training, funding and policy) interventions have shown to reduce absenteeism from school, respiratory infections and diarrhoea [48].

\section{Limitations of the study}

Secondary education enrolment ratio was $95.3 \%$ in UAE in 2016 [49], meaning that out-off school adolescents were excluded in this UAE GSHS. A few study variables (such as alcohol use, drug use and sexual behaviour) were excluded in the present analysis, since they had not been measured in all three of the UAE GSHS. Further study limitations include the cross-sectional study design and the self-report of the data, in particular height and body weight. Several studies $[50,51]$ comparing selfreport and measured height and weight among adolescents, conclude that self-reported BMI may be used as a valid tool to estimate BMI overweight/obesity in epidemiological studies and that self-reported BMI may be an underestimate. Further, it has been shown in previous research that anonymous self-report questionnaires may generate more accurate data on sensitive variables compared to other methods among adolescents $[52,53]$.

\section{Conclusions}

In three nationally representative surveys of in-school adolescents over a period of 11 years in the UAE, a significant reduction of being physically attacked, inadequate fruit intake, inadequate vegetable consumption, and loneliness were found among both boys and girls, while among girls only poor oral hygiene ( $<2$ times tooth brushing/day) and among boys only, experiencing hunger and in physical fight declined. Significant rises were identified among both sexes in the prevalence of bullying victimization, overweight or obesity, leisure-time sedentary behaviour, injury and not always washing hands prior to eating, and among boys only obesity and among girls only inadequate physical activity, and school truancy. Several poor health indicators declined but even more increased over three crosssectional surveys from 2005 to 2016 emphasizing the need for enhanced health promotion activities in this adolescent school population.

\section{Abbreviations}

GSHS: Global School-Based Student Health Survey; STATA: Statistics and data; UAE: United Arab Emirates

\section{Acknowledgements}

The data source, the World Health Organization NCD Microdata Repository (URL: https://extranet.who.int/ncdsmicrodata/index.php/catalog), is hereby acknowledged.

\begin{abstract}
Authors' contributions
All authors fulfil the criteria for authorship. SP and KP conceived and designed the research, performed statistical analysis, drafted the manuscript and made critical revision of the manuscript for key intellectual content. All authors read and approved the final version of the manuscript and have agreed to authorship and order of authorship for this manuscript.
\end{abstract}

\section{Funding}

Not applicable.

Ethics approval and consent to participate

Ethics approval was obtained from the UAE Ministry of Health and written informed consent was obtained from the participating schools, parents and students [18].

\section{Consent for publication \\ Not applicable.}

\section{Availability of data and materials}

The data for the current study are publicly available at the World Health Organization NCD Microdata Repository (URL: https://extranet.who.int/ ncdsmicrodata/index.php/catalog).

\section{Competing interests}

The authors declare that they have no competing interests.

\section{Author details}

${ }^{1}$ ASEAN Institute for Health Development, Mahidol University, Salaya, Phutthamonthon, Nakhon Pathom, Thailand. 'Department of Research Administration and Development, University of Limpopo, Polokwane, South Africa. ${ }^{3}$ Department of Psychology, University of the Free State, Bloemfontein, South Africa.

Received: 4 May 2020 Accepted: 21 July 2020

Published online: 29 July 2020

References

1. World Health Organization - Noncommunicable Diseases (NCD) Country Profiles, 2018, United Arab Emirates. URL: https://www.who.int/nmh/ countries/2018/are_en.pdf?ua=1.Accessed 2 Mar 2020.

2. Rahim HF, Sibai A, Khader Y, Hwalla N, Fadhil I, Alsiyabi H, Mataria A, Mendis S, Mokdad AH, Husseini A. Non-communicable diseases in the Arab world. Lancet. 2014;383(9914):356-67. doi:https://doi.org/10.1016/S01406736(13)62383-1.

3. World Health Organization (WHO). Global school-based student health survey (GSHS). 2020. URL: https://www.who.int/ncds/surveillance/gshs/en/. Accessed 10 Apr 2020.

4. Clark T, Fleming T, Bullen P, Crengle S, Denny S, Dyson B, Peiris-John R, Robinson E, Rossen F, Sheridan J, Teevale T, Utter J, Lewycka S. Health and well-being of secondary school students in New Zealand: trends between 2001, 2007 and 2012. J Paediatr Child Health. 2013;49(11):925-34. doi: https://doi.org/10.1111/jpc.12427.

5. Peltzer K, Pengpid S. Health Risk Behaviour among In-School Adolescents in the Philippines: Trends between 2003, 2007 and 2011, A Cross-Sectional Study. Int J Environ Res Public Health. 2015;13(1):73. doi:https://doi.org/10. 3390/ijerph13010073.

6. Pengpid S, Peltzer K. Trends of dietary behaviour, physical activity, interpersonal violence and hand hygiene behaviour among school-going adolescents in Oman: cross-sectional national surveys from 2005, 2010 and 2015. Vulnerable Child Youth Stud. 2019. DOl:https://doi.org/10.1080/ 17450128.2019.1710632. 
7. Barakat-Haddad C, Siddiqua A. Injuries among adolescents in the United Arab Emirates. Inj Prev. 2014;20(2):121-7. https://doi.org/10.1136/injuryprev2012-040625.

8. Rigby K, Haroun D, Ali E. Bullying in schools in the United Arab Emirates and the personal safety of students. Child Indic Res 2018;12(1):DOl:https:// doi.org/10.1007/s12187-018-9603-y.

9. Alshareef N, Hussein H, Al Faisal W, El Sawaf E, Wasfy A, AlBehandy N, et al. Person, place and time characteristics of physical violence among adolescents in Dubai / UAE. Int J Prev Med Res. 2015;1(4):173-8. http://www.aiscience.org/ journal/ijpmr.

10. Al Junaibi A, Abdulle A, Sabri S, Hag-Ali M, Nagelkerke N. The prevalence and potential determinants of obesity among school children and adolescents in Abu Dhabi, United Arab Emirates. Int J Obes. 2013;37(1):6874. https://doi.org/10.1038/ijo.2012.131.

11. Makansi N, Allison P, Awad M, Bedos C. Fruit and vegetable intake among Emirati adolescents: a mixed methods study. East Mediterr Health J. 2018; 24(7):653-63. doi:https://doi.org/10.26719/2018.24.7.653.

12. Yammine $K$. The prevalence of physical activity among the young population of UAE: a meta-analysis. Perspect Public Health. 2017;137(5):27580. https://doi.org/10.1177/1757913916675388.

13. Siddiqua A, Dghaim R, Barakat-Haddad C. Sociodemographic predictors of tobacco smoking among expatriate and national adolescents in the United Arab Emirates. East Mediterr Health J. 2018;24(3):283-94. https://doi.org/10. 26719/2018.24.3.283. Published 2018 Jun 10.

14. Shah SM, Al Dhaheri F, Albanna A, Al Jaberi N, Al Eissaee S, Alshehhi NA, Al Shamisi SA, Al Hamez MM, Abdelrazeq SY, Grivna M, Betancourt TS. Selfesteem and other risk factors for depressive symptoms among adolescents in United Arab Emirates. PLoS One. 2020;15(1):e0227483. doi:https://doi.org/ 10.1371/journal.pone.0227483.

15. Al-Yateem N, Bani Issa W, Rossiter RC, Al-Shujairi A, Radwan H, Awad M, Fakhry R, Mahmoud I. Anxiety related disorders in adolescents in the United Arab Emirates: a population based cross-sectional study. BMC Pediatr. 2020; 20(1):245. doi:https://doi.org/10.1186/s12887-020-02155-0.

16. World Health Organization. Regional Office for the Eastern Mediterranean. Health-promoting schools initiative in Oman: a WHO case study in intersectoral action / World Health Organization. Regional Office for the Eastern Mediterranean. 2013. URL: http://applications.emro.who.int/dsaf/ EMROPUB_2013_EN_1587.pdf. Accessed 2 May 2019.

17. Cole TJ, Bellizzi MC, Flegal KM, Dietz WH. Establishing a standard definition for child overweight and obesity worldwide: international survey. BMJ. 2000; 320:1240-3.

18. Centers for Disease Control (CDC). State indicator report on fruits and vegetables. 2013. Available online: http://www.cdc.gov/nutrition/downloads/ state-indicator-reportfruits-vegetables-2013.pdf (Accessed 10 Oct 2019).

19. World Health Organization. Physical activity fact sheet. 2017. URL: http:// www.who.int/mediacentre/factsheets/fs385/en/. Accessed 10 Oct 2019.

20. Guthold R, Cowan MJ, Autenrieth CS, Kann L, Riley LM. Physical activity and sedentary behavior among schoolchildren: a 34-country comparison. J Pediatr. 2010;157:43-9. doi:https://doi.org/10.1016/j.jpeds.2010.01.019. e1.

21. Al Matroushi M. Chapter 20 United Arab Emirates: Health-Promoting Schools: Strategies for Policy Change. C. Vince Whitman and C.E. Aldinger, editors Studies in Global School Health Promotion: From Research to Practice (pp. 265-282). New: Springer. DOl: https://doi.org/10.1007/978-0387-92269-0_20.

22. Awofeso N, Zarooni A, Rabih Z, Bamidele M. Health Literacy Measurements with The Newest Vital Sign Instrument Among Adolescents from Dubai, United Arab Emirates. TJFMPC. 2017;11(3):164-70.

23. AlBlooshi A, Shaban S, AlTunaiji M, Fares N, AlShehhi L, AlShehhi H, AlMazrouei A, Souid AK. Increasing obesity rates in school children in United Arab Emirates. Version 2. Obes Sci Pract. 2016;2(2):196-202. https:// doi.org/10.1002/osp4.37.

24. NCD Risk Factor Collaboration (NCD-RisC). Collaborators. (1040) Worldwide trends in body-mass index, underweight, overweight, and obesity from 1975 to 2016: a pooled analysis of 2416 population-based measurement studies in 128.9 million children, adolescents, and adults. Lancet 2017;390(10113): 2627e42. doi: https://doi.org/10.1016/S01406736(17)32129-3.

25. Al Ani MF, Al Subhi LK, Bose S. Consumption of fruits and vegetables among adolescents: a multi-national comparison of eleven countries in the Eastern Mediterranean Region. Br J Nutr. 2016;115(6):1092-9. doi:https://doi. org/10.1017/S0007114515005371.
26. Finkelhor D, Turner HA, Shattuck A, Hamby SL. Prevalence of Childhood Exposure to Violence, Crime, and Abuse: Results From the National Survey of Children's Exposure to Violence. JAMA Pediatr. 2015;169(8):746-54. doi: https://doi.org/10.1001/jamapediatrics.2015.0676.

27. Chester KL, Callaghan M, Cosma A, Donnelly P, Craig W, Walsh S, Molcho M. Cross-national time trends in bullying victimization in 33 countries among children aged 11, 13 and 15 from 2002 to 2010. Eur J Public Health. 2015; 25(Suppl 2):61-4. doi:https://doi.org/10.1093/eurpub/ckv029.

28. Vieno A, Lenzi M, Gini G, Pozzoli T, Cavallo F, Santinello M. Time trends in bullying behavior in Italy. J Sch Health. 2015;85(7):441-5. doi:https://doi.org/ 10.1111/josh.12269.

29. Granero R, Poni ES, Escobar-Poni BC, Escobar J. Trends of violence among 7th, 8th and 9th grade students in the state of Lara, Venezuela: The Global School Health Survey 2004 and 2008. Arch Public Health. 2011;69(1):7. doi: https://doi.org/10.1186/0778-7367-69-7.

30. Shaikh MA. Prevalence, correlates, and changes in injury epidemiology between 2006 and 2010 among 13-15 year Moroccan school attending adolescents. J Pak Med Assoc. 2015;65(5):552-4.

31. Henry CJ, Lightowler HJ, Al-Hourani HM. Physical activity and levels of inactivity in adolescent females ages 11-16 years in the United Arab Emirates. Am J Hum Biol. 2004;16(3):346-53. doi:https://doi.org/10.1002/ajhb.20022.

32. Vancampfort D. Van Damme T, Firth J, Hallgren M, Smith L, Stubbs B, Rosenbaum S, Koyanagi A. Correlates of leisure-time sedentary behavior among 181,793 adolescents aged 12-15 years from 66 low- and middleincome countries. PLoS One. 2019;14(11):e0224339. doi: https://doi.org/10. 1371/journal.pone.0224339.

33. Al Subhi LK, Bose S, Al Ani MF. Prevalence of physically active and sedentary adolescents in 10 Eastern Mediterranean countries and its relation with age, sex, and body mass index. J Phys Act Health. 2015;12(2):257-65. doi:https:// doi.org/10.1123/jpah.2013-0134.

34. Bassett DR, John D, Conger SA, Fitzhugh EC, Coe DP. Trends in Physical Activity and Sedentary Behaviors of United States Youth. J Phys Act Health. 2015;12(8):1102-11. doi:https://doi.org/10.1123/jpah.2014-0050.

35. Peltzer K, Pengpid S. Oral and hand hygiene behaviour and risk factors among in-school adolescents in four Southeast Asian countries. Int J Environ Res Public Health. 2014;11(3):2780-92. doi:https://doi.org/10.3390/ ijerph110302780.

36. ur Rehman MM, Mahmood N, ur Rehman B. The relationship of caries with oral hygiene status and extra-oral risk factors. J Ayub Med Coll Abbottabad. 2008;20(1):103-8.

37. Khadri FA, Gopinath VK, Hector MP, Davenport ES. Evaluating the risk factors that link obesity and dental caries in 11-17-year-old school going children in the United Arab Emirates. Eur J Dent. 2018;12(2):217-24. https://doi.org/ 10.4103/ejd.ejd_29_18.

38. Ghanim M, Dash N, Abdullah B, Issa H, Albarazi R, Saheli ZA. Knowledge and Practice of Personal Hygiene among Primary School Students in SharjahUAE. J Health Sci. 2016;6(5):67-73. DOl:https://doi.org/10.5923/j.health. 20160605.01.

39. Afifi HS, Abushelaibi AA. Assessment of personal hygiene knowledge, and practices in Al Ain, United Arab Emirates. Food Control. 2012;25(1):249-53. DOl:https://doi.org/10.1016/j.foodcont.2011.10.040.

40. Global Youth Tobacco Survey. United. Arab Emirates F. 2005: URL: http:// www.emro.who.int/images/stories/tfi/documents/gyts_fs_uae_r2.pdf?ua=1 Accessed 2 May 2020

41. Global Youth Tobacco Survey. United. Arab Emirates F. 2013: URL: http:// www.emro.who.int/images/stories/tfi/documents/gyts_fs_uae_2013.pdf?ua= 1. Accessed 2 May 2020

42. Yuksel HS, Şahin FN, Maksimovic N, Drid P, Bianco A. School-Based Intervention Programs for Preventing Obesity and Promoting Physical Activity and Fitness: A Systematic Review. Int J Environ Res Public Health. 2020;17(1):347. doi:https://doi.org/10.3390/ijerph17010347.

43. Liu Z, Xu HM, Wen LM, Peng YZ, Lin LZ, Zhou S, Li WH, Wang HJ. A systematic review and meta-analysis of the overall effects of school-based obesity prevention interventions and effect differences by intervention components. Int J Behav Nutr Phys Act. 2019;16(1):95. doi:https://doi.org/10. 1186/s12966-019-0848-8.

44. Beets MW, Beighle A, Erwin HE, Huberty JL. After-school program impact on physical activity and fitness: a meta-analysis. Am J Prev Med. 2009;36(6):52737. doi:https://doi.org/10.1016/j.amepre.2009.01.033.

45. Micha R, Karageorgou D, Bakogianni I, Trichia E, Whitsel LP, Story M, Peñalvo J, Mozaffarian D. Effectiveness of school food environment policies on 
children's dietary behaviors: A systematic review and meta-analysis. PLoS One. 2018;13(3):e0194555. doi:https://doi.org/10.1371/journal.pone.0194555.

46. Shackleton N, Jamal F, Viner RM, Dickson K, Patton G, Bonell C. SchoolBased Interventions Going Beyond Health Education to Promote Adolescent Health: Systematic Review of Reviews. J Adolesc Health. 2016;58(4):382-96. doi:https://doi.org/10.1016/.jadohealth.2015.12.017.

47. Dray J, Bowman J, Campbell E, Freund M, Wolfenden L, Hodder RK, McElwaine K, Tremain D, Bartlem K, Bailey J, Small T, Palazzi K, Oldmeadow C, Wiggers J. Systematic Review of Universal Resilience-Focused Interventions Targeting Child and Adolescent Mental Health in the School Setting. J Am Acad Child Adolesc Psychiatry. 2017;56(10):813-24. doi:https:// doi.org/10.1016/j.jaac.2017.07.780

48. Mbakaya BC, Lee PH, Lee RL. Hand Hygiene Intervention Strategies to Reduce Diarrhoea and Respiratory Infections among Schoolchildren in Developing Countries: A Systematic Review. Int J Environ Res Public Health. 2017;14(4):371. Published 2017 Apr 1. doi:https://doi.org/10.3390/ ijerph14040371.

49. Fonseca H, Silva AM, Matos MG, Esteves I, Costa P, Guerra A, Gomes-Pedro J. Validity of BMI based on self-reported weight and height in adolescents. Acta Paediatr. 2010;99(1):83-8. doi:https://doi.org/10.1111/j.1651-2227.2009. 01518.x.

50. Brener ND, Mcmanus T, Galuska DA, Lowry R, Wechsler H. Reliability and validity of self-reported height and weight among high school students. J Adolesc Health. 2003;32(4):281-7. doi:https://doi.org/10.1016/s1054139x(02)00708-5.

51. UNESCO. United Arab Emirates, Participation in Education. 2019. URL: http:// uis.unesco.org/en/country/ae.Accessed 2 Apr 2020.

52. Carvalho AF, Stubbs B, Vancampfort D, Kloiber S, Maes M, Firth J, Kurdyak PA, Stein DJ, Rehm J, Koyanagi A. Cannabis use and suicide attempts among 86,254 adolescents aged 12-15 years from 21 low- and middleincome countries. Eur Psychiatry. 2019;56:8-13. doi:https://doi.org/10.1016/j. eurpsy.2018.10.006.

53. Pigeon WR, Pinquart M, Conner K. Meta-analysis of sleep disturbance and suicidal thoughts and behaviors. J Clin Psychiatry. 2012;73(9):e1160-7. doi: https://doi.org/10.4088/JCP.11r07586.

\section{Publisher's Note}

Springer Nature remains neutral with regard to jurisdictional claims in published maps and institutional affiliations.

Ready to submit your research? Choose BMC and benefit from:

- fast, convenient online submission

- thorough peer review by experienced researchers in your field

- rapid publication on acceptance

- support for research data, including large and complex data types

- gold Open Access which fosters wider collaboration and increased citations

- maximum visibility for your research: over $100 \mathrm{M}$ website views per year

At BMC, research is always in progress.

Learn more biomedcentral.com/submissions 